\title{
Robust Neuroprosthetic Control from the Stroke Perilesional Cortex
}

\author{
- TTanuj Gulati, ${ }^{1,3}$ Seok Joon Won, ${ }^{1,3}$ Dhakshin S. Ramanathan, ${ }^{1,2,4}$ Chelsea C. Wong, ${ }^{1,3}$ Anitha Bodepudi, ${ }^{1,3}$ \\ - Raymond A. Swanson, ${ }^{1,3}$ and Karunesh Ganguly ${ }^{1,3}$ \\ ${ }^{1}$ Neurology and Rehabilitation Service and 2Department of Psychiatry, San Francisco Veterans Affairs Medical Center, San Francisco, California 94158, \\ ${ }^{3}$ Department of Neurology, University of California San Francisco, San Francisco, California 94158, and ${ }^{4}$ Department of Psychiatry, University of California \\ San Francisco, San Francisco, California 94143
}

Intracortical brain-machine interfaces (BMIs) may eventually restore function in those with motor disability after stroke. However, current research into the development of intracortical BMIs has focused on subjects with largely intact cortical structures, such as those with spinal cord injury. Although the stroke perilesional cortex (PLC) has been hypothesized as a potential site for a BMI, it remains unclear whether the injured motor cortical network can support neuroprosthetic control directly. Using chronic electrophysiological recordings in a rat stroke model, we demonstrate here the PLC's capacity for neuroprosthetic control and physiological plasticity. We initially found that the perilesional network demonstrated abnormally increased slow oscillations that also modulated neural firing. Despite these striking abnormalities, neurons in the perilesional network could be modulated volitionally to learn neuroprosthetic control. The rate of learning was surprisingly similar regardless of the electrode distance from the stroke site and was not significantly different from intact animals. Moreover, neurons achieved similar task-related modulation and, as an ensemble, formed cell assemblies with learning. Such control was even achieved in animals with poor motor recovery, suggesting that neuroprosthetic control is possible even in the absence of motor recovery. Interestingly, achieving successful control also reduced locking to abnormal oscillations significantly. Our results thus suggest that, despite the disrupted connectivity in the PLC, it may serve as an effective target for neuroprosthetic control in those with poor motor recovery after stroke.

Key words: brain-machine interface; electrophysiology; plasticity; stroke

\section{Introduction}

Research into the development of intracortical brain-machine interfaces (BMIs) has flourished over the past decade, leading to demonstrations of direct neural control of prosthetic devices in real-time through modulation of neural signals (Chapin et al., 1999; Serruya et al., 2002; Taylor et al., 2002; Carmena et al., 2003; Musallam et al., 2004; Hochberg et al., 2006; Santhanam et al., 2006; Jarosiewicz et al., 2008; Moritz et al., 2008; Velliste et al., 2008; Ganguly et al., 2009; Hochberg et al., 2012; Collinger et al., 2013). Taskdependent volitional modulation of the activity of selected neurons is also closely tied to the concept of BMIs (Fetz, 1969; Ganguly and Carmena, 2009; Koralek et al., 2010; Ganguly et al.,

Received Dec. 9, 2014; revised April 29, 2015; accepted May 4, 2015.

Author contributions: T.G., S.-J.W., R.S., and K.G. designed research; T.G., S.-J.W., C.C.W., and K.G. performed research; T.G., S.J.W., D.S.R., C.C.W., R.A.S., and K.G. contributed unpublished reagents/analytic tools; T.G. and A.B. analyzed data; T.G. and K.G. wrote the paper.

This work is supported by the Department of Veterans Affairs (Grant B6674 to K.G.), the Burroughs Wellcome Fund (Grant 1009855 to K.G.), the American Heart/Stroke Association (Grant $0875016 \mathrm{~N}$ to K.G.), and by start-up funds from the SFVAMC, NCIRE, and UCSF Department of Neurology; an Advanced Research Fellowship from the VA to D.R.

The authors declare no competing financial interests.

Correspondence should be addressed to Karunesh Ganguly, Neurology and Rehabilitation Service, San Francisco Veterans Affairs Medical Center, 1700 Owens Street, San Francisco, CA 94158. E-mail: karunesh.ganguly@ucsf.edu.

DOI:10.1523/JNEUROSCI.5007-14.2015

Copyright $\odot 2015$ the authors $\quad 0270-6474 / 15 / 358653-09 \$ 15.00 / 0$
2011). Together, this body of work has also indicated that neural plasticity likely plays an important role in achieving stable neuroprosthetic control (Taylor et al., 2002; Jarosiewicz et al., 2008; Moritz et al., 2008; Ganguly and Carmena, 2009; Koralek et al., 2010; Arduin et al., 2013; Gulati et al., 2014). Importantly, this research into the development of intracortical BMIs has primarily focused on subjects with intact cortical structures.

In contrast, the development of BMIs specifically compatible with stroke (Langhorne et al., 2011; Norrving and Kissela, 2013) or other forms of direct cortical injury requires a greater understanding of the neurophysiology of the injured neural network (Nudo et al., 1996; Ward, 2004; Dancause, 2006; Cramer, 2008; Murphy and Corbett, 2009). Although both the perilesional cortex (PLC) surrounding the injury (Daly and Wolpaw, 2008; Guggenmos et al., 2013) and motor areas in the unaffected hemisphere are possible targets of neural interfaces after stroke, more attention has been placed on the unaffected contralateral hemisphere (Bundy et al., 2012). This interest may have been fueled by findings of an increased role of the contralesional hemisphere in movements of the ipsilateral limb after stroke (Brinkman and Kuypers, 1973; Dancause, 2006; Hummel and Cohen, 2006). However, the PLC is an important site of reorganization after stroke (Nudo and Milliken, 1996; Brown et al., 2010); moreover, task-specific rehabilitation is also known to have synergistic effects on perilesional cortical plasticity (Nudo et al., 1996; Bier- 
naskie and Corbett, 2001; Ramanathan et al., 2006). It remains unknown whether the impaired local structural and functional connectivity present after stroke (Nudo et al., 1996; Ward, 2004; Dancause, 2006; Cramer, 2008; Murphy and Corbett, 2009; Guggenmos et al., 2013) can support neuroprosthetic control. By adapting chronic electrophysiological recordings to a rodent stroke model, we investigated the electrophysiological characteristics of the injured PLC and whether its spiking activity can be modulated volitionally to control an artificial actuator. We also measured directly the physiological plasticity induced by neuroprosthetic learning in the poststroke PLC.

\section{Materials and Methods}

Animals and surgery

Experiments were approved by the Institutional Animal Care and Use Committee at the San Francisco Veterans Affairs Medical Center. We used 13 adult Long-Evans male rats ( $\sim 8$ weeks old). Animals were kept under controlled temperature and a $12 \mathrm{~h}$ light: $12 \mathrm{~h}$ dark cycle with lights on at 6:00 A.M. Probes were implanted during a recovery surgery performed under isofluorane (1-3\%) anesthesia after induction with ketamine $[2 \mathrm{mg} / \mathrm{kg}$ body weight (b.w.) ] and xylazine (1 $\mathrm{mg} / \mathrm{kg}$ b.w.). Atropine sulfate was also administered before anesthesia $(0.02 \mathrm{mg} / \mathrm{kg}$ b.w.). In eight rats, a focal photothromobotic stroke was induced in the upper limb primary motor cortex area (M1). For this, unilateral femoral vein cannulation was done before craniotomy and an intravenous catheter was placed for rose-bengal dye injection. After this, the head was fixed in the stereotaxic frame and a craniotomy was performed. Stroke was induced via illumination with white light (KL-500) using a fiber optic cable for $15 \mathrm{~min}$. We used a $3 \mathrm{~mm}$ aperture for stroke induction (centered in the M1 area based on stereotactic coordinates) and covered the remaining cortical area with a custom mask to prevent light penetration. After induction, a probe was implanted immediately in PLC with one of the outermost rows of the array implanted immediately proximal to the stroke site (see Fig. 1A). The postoperative recovery regimen included administration of buprenorphine at $0.02 \mathrm{mg} / \mathrm{kg}$ b.w and meloxicam at $0.2 \mathrm{mg} / \mathrm{kg}$ b.w. Dexamethasone at $0.5 \mathrm{mg} / \mathrm{kg} \mathrm{b.w.} \mathrm{and}$ Trimethoprim sulfadiazine at $15 \mathrm{mg} / \mathrm{kg}$ b.w. were also administered postoperatively for $5 \mathrm{~d}$. All animals were allowed to recover for $5 \mathrm{~d}$ before start of experiments.

\section{Electrophysiology}

We recorded extracellular neural activity using tungsten microwire electrode arrays (MEAs, $n=13$ rats; Tucker-Davis Technologies). We used either 16- or 32-channel arrays (33 $\mu \mathrm{m}$ polyimide-coated tungsten microwire arrays). Arrays were lowered down to $1500-1800 \mu \mathrm{m}$ in M1 (1-3 $\mathrm{mm}$ anterior to bregma and $2-4 \mathrm{~mm}$ lateral from midline or immediately proximal to the stroke site). Final localization of depth was based on quality of recordings across the array at the time of implantation. We recorded spike and LFP activity using a 128-channel TDT-RZ2 system (Tucker-Davies Technologies). Spike data were sampled at $24414 \mathrm{~Hz}$ and LFP data at $1018 \mathrm{~Hz}$. ZIF-clip-based analog headstages with a unity gain and high impedance $(\sim 1 G \Omega)$ were used. Only clearly identifiable units with stable waveforms and a high signal-to-noise ratio (SNR) were used for these experiments. To calculate the SNR, we used following equation:

$$
S N R=\frac{A}{2 * S D_{\text {noise }}}
$$

Where $A$ is the peak-to-peak voltage of the averaged spike waveform and $S D_{\text {noise }}$ is the SD of the noise (Suner et al., 2005). Unit clusters with SNR $>5$ were used for subsequent analysis. A total of 258 cells were recorded from all the rats. After the above online sorting, we also used standard offline cluster cutting methods in TDT's OpenSorter software to confirm quality of recordings. Behavior-related timestamps (i.e., trial onset, trial completion) were sent to the RZ2 analog input channel using an Arduino digital board and synchronized to neural data.

\section{Behavior}

Before surgery, animals were acclimated and then trained in a reach to grasp single pellet task after determination of handedness. After the per-
Table 1. BMI sessions

\begin{tabular}{lcccc}
\hline & \multicolumn{3}{l}{ BMl sessions } & \\
\cline { 2 - 4 } Stroke $(n=8)$ & Near & Mid & Far & Total sessions \\
\hline Rat 1 & 0 & 2 & 2 & 4 \\
Rat 2 & 2 & 1 & 0 & 3 \\
Rat 3 & 0 & 0 & 1 & 1 \\
Rat 4 & 3 & 5 & 4 & 12 \\
Rat 5 & 3 & 3 & 3 & 9 \\
Total & 8 & 11 & 10 & 29 \\
Control stroke (no BMI, $n=3)$ & 0 & & & 0 \\
Control $(n=5)$ & 13 & & & 13
\end{tabular}

Table summarizes the number of BMI sessions recorded from the near, mid, and far sites in stroke rats and intact rats

formance plateaued (typically $>75 \%$ accuracy), animals underwent either control implantation in M1 $(n=5)$ or in the PLC $(n=8)$. After recovery, animals were allowed to rest for a few days before the start of experimental sessions. Animals were also acclimated to a custom Plexiglas behavioral box for the BMI task. Five of the stroke rats underwent BMI training; three others served as the no BMI training control group. Animals were then water scheduled such that water from the feeding tube was available in a randomized fashion while in the behavioral box. We also tested their reach performance on the reach to grasp task. During this period, we closely monitored the animals and ensured that body weights did not drop below $95 \%$ of the initial weight. Reach sessions were typically conducted in the morning (consisting of 25 trials). This was then followed by the brain-control task for a period of $1-2 \mathrm{~h}$. Recorded neural data were entered in real time to custom routines in MATLAB (The MathWorks). These then served as control signals for the angular velocity of the feeding tube. The rats typically performed $\sim 100-200$ trials during these sessions.

\section{Neural control of the feeding tube}

During the direct neural control training sessions, we selected well isolated neurons and allowed their spiking activity to control the angular velocity of the feeding tube. We binned the spiking activity into $100 \mathrm{~ms}$ bins. We then established a mean firing rate for each neuron over a 3-5 min baseline period. The mean firing rate was then subtracted from its current firing rate at all times. To test the capacity for neuroprosthetic control, the specific transform used was as follows:

$$
\Theta_{\mathbf{v}}=C *\left[W_{+} * r_{1}+W_{-} * r_{2}\right]
$$

Where $\theta_{\mathrm{v}}$ was the angular velocity of the feeding tube, and $W_{+}=+1$ and $W_{-}=-1, r_{1}$ and $r_{2}$ were the firing rates of the units chosen. In both cases, $C$ was a fixed constant that scaled the firing rates to angular velocity. The animals were then allowed to control the feeding tube via modulation of neural activity. In some stroke rats, for initial sessions, only $W_{+}$was used to get the rats used to PLC volitional modulation. Data from these sessions are not presented here. The tube started at the same position at the onset of each trial. The calculated angular velocity was added to the previous angular position at each time step (100 ms). During each trial, the angular position could range from -45 to +180 degrees. If the tube stayed in the "target zone" for a period of $300 \mathrm{~ms}$, a water reward was delivered. In the beginning of a session, most rats were unsuccessful at bringing the feeding tube to the rewarded position. Most rats steadily improved control and reduced the time to completion of the task during the first session. As shown in Table 1, multiple learning sessions were obtained from each animal. Consistent with past studies, we also found that incorporation of new units into the control scheme required new learning (Moritz et al., 2008; Ganguly and Carmena, 2009).

\section{Data analysis}

Stroke perilesional neurophysiology. Several custom-written routines in MATLAB (The MathWorks) were used for analyzing the spontaneous neurophysiology in the stroke and control animals. Spontaneous periods (up to $\sim 5 \mathrm{~min}$ ) were selected from recording blocks when no BMI training was initiated and LFP recordings were used for power spectral density analysis. In the three rats with stroke but no BMI training, spontaneous segments were of similar duration to that of the stroke rats that under- 
went BMI training. We used the Chronux toolbox to calculate both power spectrum and spike-field coherence (SFC; Mitra and Bokil, 2008). SFC measures phase synchronization between the LFP and spike times as a function of frequency. The magnitude of SFC is a function of frequency and takes values between 0 and 1 . We segmented the spontaneous periods into $15 \mathrm{~s}$ segments and then averaged the coherency measures across segments. Spontaneous segments lasted 3-10 min preceding or after direct neural control. Because the SFC can vary due to the number of spikes that are used to calculate it (Zeitler et al., 2006), we equaled the number of spikes in the spontaneous segments by randomly selecting a subsample of spikes from the group with greater number of spikes (Mitchell et al., 2009; Rutishauser et al., 2010). For the multitaper analyses we used a time-bandwidth (TW) product of 4 with 7 tapers. To compare coherences across groups, a $z$-score was calculated using the programs available in the Chronux toolkit. Coherence between activity in two regions was calculated and defined as follows:

$$
C_{\mathrm{xy}}=\frac{\left|R_{\mathrm{xy}}\right|}{\sqrt{\left|R_{\mathrm{xx}}\right|} \sqrt{\left|R_{\mathrm{yy}}\right|}}
$$

Where $R_{\mathrm{xx}}$ and $R_{\mathrm{yy}}$ are the power spectra and $R_{\mathrm{xy}}$ is the cross-spectrum. Spectral analyses were calculated in segmented spontaneous epochs and averaged across these epochs across animals. Mean coherences were calculated in the delta $(\delta, 0.3-4 \mathrm{~Hz})$, theta $(\theta, 6-10 \mathrm{~Hz})$, alpha $(\alpha, 8-15 \mathrm{~Hz})$, beta $(\beta, 18-25 \mathrm{~Hz})$, and gamma $(\gamma, 30-60 \mathrm{~Hz})$ frequency band ranges. Significance testing on coherence magnitudes was performed using $t$ tests for comparisons in stroke and control animals in different frequency ranges. The power spectrum of the LFP channels used in the coherence calculation, as well as for overall power change in spontaneous segments, was also determined using the multitaper method.

Sessions and changes in performance. A total of 42 training sessions (recorded from the 10 rats) were used for our analyses. Thirteen BMI sessions were recorded in five control animals and $29 \mathrm{BMI}$ sessions were recorded in five stroke animals. Table 1 summarizes the session details. Sessions in stroke animals were recorded when the upper limb was still substantially impaired (i.e., poor performance on the reach to grasp task). Changes in task performance were compared between and across sessions. Specifically, we compared the performance change between early and late trials by calculating the mean and SE of the time to completion during the last 30 trials and the first 30 trials in a session. The percentage improvement was calculated from these values. We also assessed the proportion of unsuccessful trials in these early and late trial segments. We used a paired $t$ test to assess statistical significance and one-way ANOVA to see improvement changes between groups. In select sessions, we videotaped the rat during BMI training blocks. Also consistent with multiple reports, we did not observe movements that systematically predicted feeding tube movements (Ganguly et al., 2011; Koralek et al., 2012). Specifically, we analyzed whether limb movements measured using the video recording (i.e., markers manually assigned to the head, torso, and each limb using image processing software) covaried with movements of the feeding tube. Across multiple sessions, we did not find evidence for significant covariation (data not shown). This is likely due to the fact that non-movement-related random weights were assigned to the decoder units.

Ensemble activation analyses. We used activation strength analysis (Peyrache et al., 2009; Lopes-dos-Santos et al., 2013; Gulati et al., 2014) to estimate the similarity of neural activity patterns in late trials and early trials using the "instantaneous activation strength matrix." This analysis examines the evolution of stereotyped ensemble activity with learning. For this, we used both the "direct" neural activity (i.e., units causally liked to BMI control by the transform) and the "indirect" activity (i.e., activity that was recorded but not used for BMI control (Ganguly et al., 2011). Therefore, an increase in activation would indicate that there is coincident activation of neural activity and the formation of cell assemblies. We consistently observed that the transition to a plateau performance levels heralded the transition to increased activation. For this analysis, we first computed a pairwise neural activity correlation matrix (spike trains were binned, $\Delta t_{\text {bin }}=50 \mathrm{~ms}$ ). The eigenvector with the largest eigenvalue in this correlation matrix served as the learning-related cell assembly. Spe- cifically, the obtained spike counts for each cell $\left[s^{i}(t), i=1: n, t=1: B\right.$, where $n$ is the number of cells and $B$ is the number of time bins in the epoch] were $z$-scored, obtaining the $Q$ matrix as follows:

$$
Q=\frac{s^{i}(t)-<s^{i}>}{\sigma_{s^{i}}}
$$

where $\left\langle s^{i}\right\rangle$ is the mean and is $\sigma_{s^{i}}$ is the SD. The pairwise cell activity correlation matrix can be presented in following equation:

$$
C=\frac{1}{B} Q Q^{t}
$$

We thus obtained spike count matrices, $Q_{\mathrm{BMI}}$, and the correlation matrices $C_{\mathrm{BMI}}$. Peyrache et al. (2009) further proposed the use of the Marcenko-Pastur distribution as the null hypothesis for the existence of cell assemblies. It was demonstrated that eigenvalues of the correlation matrix of a normal random matrix $R$ with statistically independent rows follows a probability distribution described as follows:

$$
\mathrm{p}(\lambda)=\frac{q}{2 \pi \sigma^{2}} \frac{\sqrt{\left(\lambda_{\max }-\lambda\right)\left(\lambda-\lambda_{\min }\right)}}{\lambda}
$$

Where $\lambda_{\min }^{\max }=\sigma^{2}(1 \pm \sqrt{1 / q})^{2}$ and $\sigma^{2}$ is the variance of the elements of the random matrix $R$, which is 1 here (due to $z$ scoring), and $q=R_{\text {columns }}$ l $R_{\text {rows }} \geq 1$. Under the null hypothesis of an uncorrelated matrix, the correlations between spike trains are determined only by random fluctuations and the eigenvalues of template awake matrix must lie between $\lambda_{\min }$ and $\lambda_{\max }$. Eigenvalues greater than $\lambda_{\max }$ are therefore a sign of nonrandom correlations in the matrix and, for this reason, we refer to these principal components as signal. A reactivation time series measured the instantaneous match of this cell assembly to the ongoing activity (Peyrache et al., 2009). The output of this analysis are principle components (PCs), consisting of an array of weights assigned to each unit in the identified ensemble, and the eigenvalue, a numerical value that represents the extent of total variance that is captured by a given PC (PCs with the largest eigenvalues capture the most variance) and also an instantaneous activation strength of these signal components. Whether a calculated PC represents a significant temporally correlated pattern of activity is determined by $\lambda_{\max }$, the highest eigenvalue that arises out of an equivalently sized random matrix based on the Marchenko-Pastur. Therefore, PCs with eigenvalues greater than $\lambda_{\max }$ were considered "signal components," whereas those below $\lambda_{\max }$ were considered to have arisen from chance interactions.

We started by estimating the signal components (i.e., ensemble patterns of activity) linked to successful learning. For quantification of the instantaneous activation, we isolated the reactivations of identified cell assembly in early and late trials. We specifically examined the first $4 \mathrm{~s}$ after the "GO" cue was given. We also averaged the respective values for the first 30 trials (i.e., early) and the last 30 trials (i.e., late). For comparison across stroke and control learning sessions, we compared the peak activation during early and late trials.

\section{Statistical analysis}

We performed one-way ANOVA with multiple comparisons wherever significance assessment was required in more than three groups. We also used a paired $t$ test for comparisons between early and late trials features (e.g., time to reward and proportion of unsuccessful trials in and early and late trials, etc.). We also used linear regression to evaluate trends between reach success and improvement/rate of learning in BMI sessions.

\section{Results}

Microwire probes were inserted into the PLC of five rats immediately after a photothrombotic stroke of the upper-limb M1. The efficacy of stroke was determined by histological examination (Fig. 1A) and the ability to perform a single-pellet reach and grasp task (Foroud and Whishaw, 2006; Wong et al., 2015). In a subset of animals, we used ex vivo microcomputerized tomography to 
A

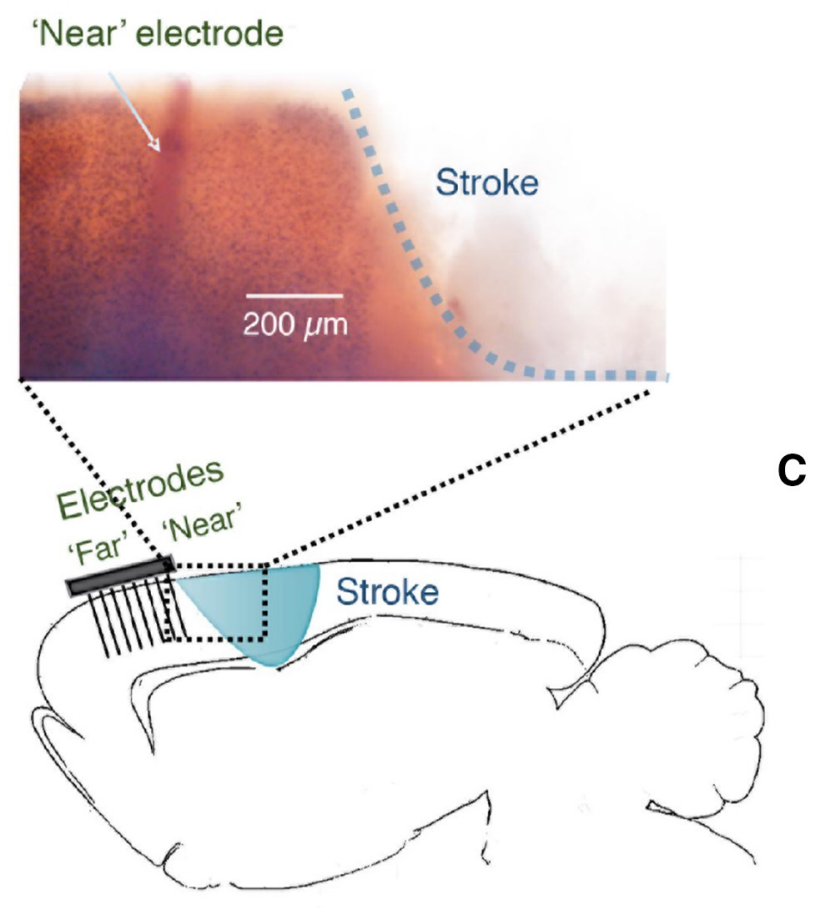

Sagittal View
B

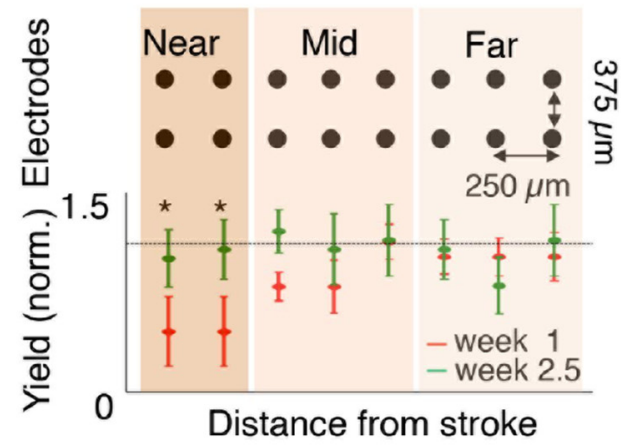

C

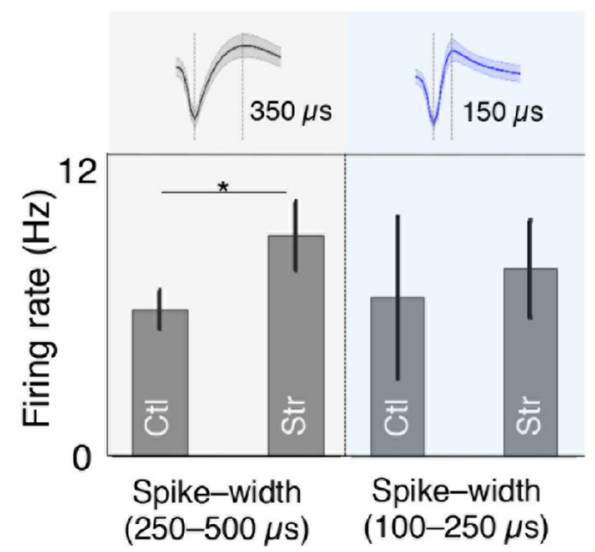

Figure 1. Spontaneous spiking activity and field oscillations in the PLC. A, Schematic of electrophysiological monitoring from the PLC. Histology above shows example sagittal view of stroke site and tract from a near electrode. $\boldsymbol{B}$, Comparison of the change in recording yield over time (week $1 \mathrm{vs}$ week 2.5) on electrodes as a function of distance from the stroke site (near, mid, and far electrodes are indicated at top). Error bars indicate SEM. ${ }^{*} p<0.01$. C, Difference in the spiking activity for broad-width (left gray column) and narrow-width units (blue right column). ${ }^{*} p<0.05$.
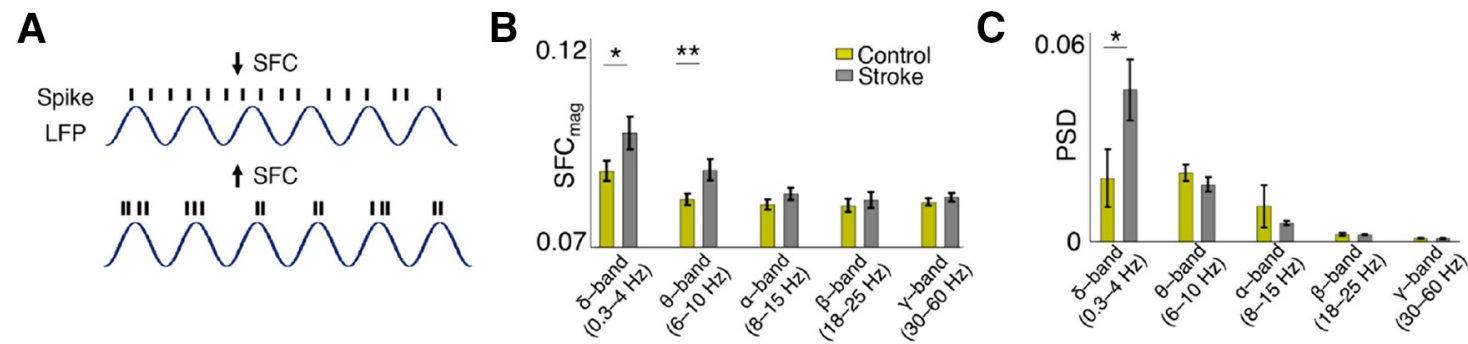

Figure 2. A, Schematic depicting SFC. Top row shows out-of-phase unit spikes and LFP indicating a lower SFC and bottom row shows phase-synchronized spikes and LFP resulting in a higher SFC. $B$, Comparison of differences in the SFC $C_{\text {mag }}$ in control and stroke animals. C, Power spectral density of LFPs in control and stroke animals. ${ }^{*} p<0.05$; ${ }^{* *} p<0.005$.

measure the infarct volume $\left(7.067 \pm 0.052, \mathrm{~mm}^{3}\right)$ and to determine the "near" electrode distance from the stroke site (580.00 \pm $137.61 \mu \mathrm{m}$; Fig. $1 A$ ). We also implanted five uninjured rats as a control group.

\section{Network dysfunction in the stroke PLC}

We first compared the recorded neural activity across the array; that is, on "near," "mid," and "far" electrodes (Fig. $1 A, B$ ). In the first week after stroke, there was a significant reduction in the number of neurons recorded on near versus far channels (oneway ANOVA, $p<10^{-4}$ ), further indicating that the implanted array was in the PLC. After 2 weeks, the distribution was similar across the array and was not significantly different from M1 recordings obtained from five intact animals (one-way ANOVA, $p>0.05)$.

Next, we assessed whether spontaneous firing rates were altered in the PLC. We grouped neurons based on the measured width of the recorded spike; past literature suggests that such measurements can distinguish putative fast spiking interneurons and pyramidal neurons (Vinck et al., 2013; Courtin et al., 2014). Interestingly, we found that neurons with broader action potentials had significantly higher spontaneous firing rate in the stroke group (compared with the control group, $t$ test, $p<0.05, n=64$ in control group and $n=33$ in stroke group for broad-width cells and $n=12$ in control group and $n=16$ in stroke group for narrow-width cells; Fig. 1C). The control group spontaneous firing rates are comparable to what has been observed for spontaneous firing in other rodent motor cortical studies (Isomura et al., 2009). We also looked at SFC magnitudes (SFC mag; Fig. 2A) for these units and found that broad-width spikes had significantly elevated $\mathrm{SFC}_{\mathrm{mag}}$ in the $\delta(0.3-4 \mathrm{~Hz})$ and $\theta(6-10 \mathrm{~Hz})$ bands compared with controls ( $t$ test, $p<0.005$; Fig. $2 B$ ). They were not significantly different for the other higher-frequency bands (i.e., $\alpha, 8-15 \mathrm{~Hz} ; \beta, 18-25 \mathrm{~Hz}$; and $\gamma, 30-60 \mathrm{~Hz}$ ). For narrow-width 
A

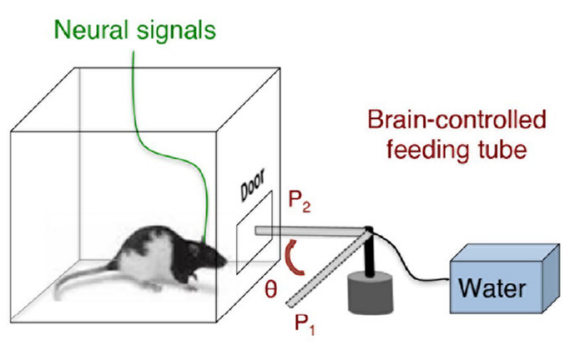

C

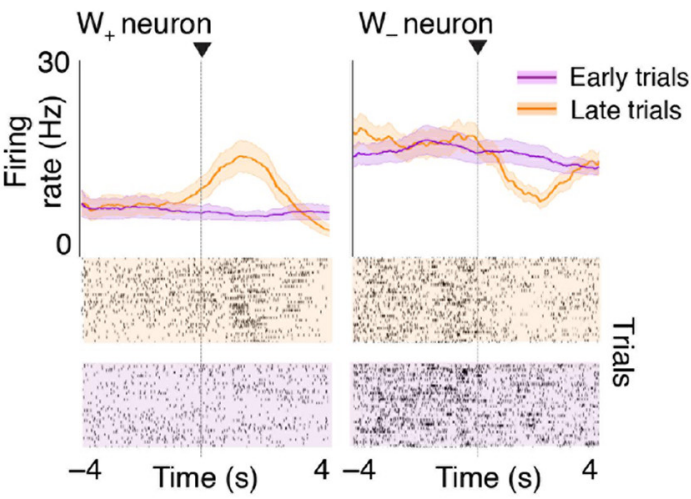

B
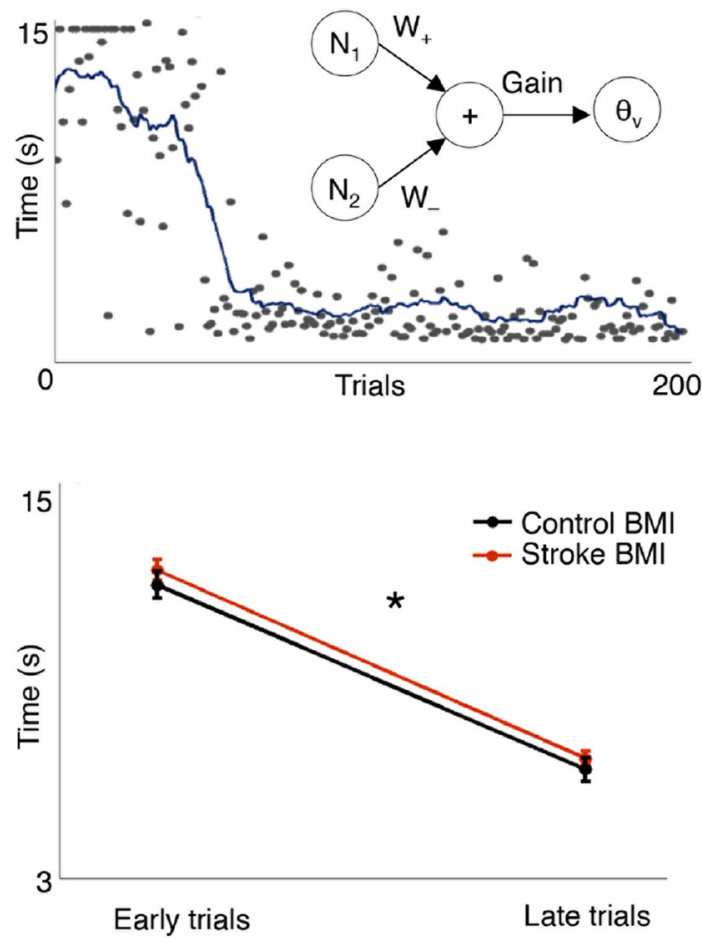

Figure 3. Direct brain control from the PLC. $A$, Schematic of the setup used to assess direct neural control of the PLC. $B$, Change in time to task completion with practice using volitional control of PLC neurons. Solid line represents mean time using a moving window of 20 trials. $W_{+}$and $W_{-}$, respectively, indicate positive and negative weights. C, Change in task-related activation for two neurons. Shown at top are the respective mean firing rates during early and late trials. Shaded region is the SEM. At the bottom are single-trial rasters from corresponding early and late periods. $\boldsymbol{D}$, Comparison of the change in time to task completion for control and stroke animals. * $p<0.01$.

units, none of the five frequencies showed a significant difference (data not shown, $p>0.05$ for all five frequency bands). Moreover, the power spectral density of the LFPs from stroke animals showed significantly elevated power in the slowest-frequency bands compared with controls ( $t$ test, $p<0.05$; Fig. $2 C$ ). These results are consistent with the notion that stroke leads to a dysfunctional network state marked by slow oscillations (Schiene et al., 1996; Carmichael and Chesselet, 2002).

\section{Direct control of the PLC spiking activity}

We next quantified whether spiking activity recorded from the electrodes in the PLC could be volitionally modulated in a taskdependent manner (Fig. 3). Specifically, spiking activity was transformed via a linear decoder into the angular velocity of a mechanical actuator that could also deliver water (see Materials and Methods and Fig. $3 A, B)$. The decoder weights were held constant during the session to rely exclusively on neural learning. Each trial started with the simultaneous delivery of an auditory tone and the opening of a door to allow access to the tube. At the start of each trial, the angular position of the tube was set to $0^{\circ}$ $\left(P_{1}\right)$. If the angular position of the tube was held for $>300 \mathrm{~ms}$ at position $P_{2}\left(90^{\circ}\right)$, a defined amount of water was delivered (i.e., successful trial). A trial was stopped if this was not achieved within $15 \mathrm{~s}$ (i.e., unsuccessful trial). At the end of a trial, the door was closed and the actuator was returned to position $P_{1}$. After a typical 1-2 $\mathrm{h}$ practice session, animals showed improvements in task performance with a steady reduction in the time to trial completion and a decrease in the number of unsuccessful trials. Figure $3 B$ shows an example of the learning curve when using near spiking activity of two neurons that were respectively assigned a positive and a negative weight. There were also bidirectional changes in the task related activation of the positive and the negative weight neurons (Fig. 3C). In 29 such training sessions in five rats, there was consistent evidence of practice-related improvements in task performance (control group $n=13$ sessions and stroke group $n=29$ sessions, paired t tests, $p<0.05$ for each comparison; Fig. $3 D$ ). Interestingly, the net drop in time to task completion was not significantly different for the stroke and the control group.

We also investigated whether there were differences in performance characteristics for neurons recorded from near, mid, and far sites. For the 29 BMI training sessions described above, eight were from near sites, 11 from mid and 10 from far sites (Table 1). When near, mid, and far sites were compared separately, the time to task completion reduced markedly for activity recorded on each sites in a manner similar to intact animals (near: $11.58 \pm$ 0.53 to $6.17 \pm 0.44 \mathrm{~s}$; mid: $12.67 \pm 0.45$ to $6.84 \pm 0.37 \mathrm{~s}$, far: $12.65 \pm 0.47$ to $7.02 \pm 0.39 \mathrm{~s}$, control: $11.92 \pm 0.41$ to $6.38 \pm$ $0.34 \mathrm{~s}$, all paired $t$ tests, $p<0.05$; Fig. $4 A$ ). Interestingly, there were also no differences compared with intact animals learning the neuroprosthetic control (one-way ANOVA, $p>0.05$ ). The proportion of unsuccessful trials dropped significantly for each group comparing early and late trials $(23.6 \pm 7.5$ to $6.1 \pm 3.2 \%$ at near sites, $t$ test, $t_{6}=4.12, p<0.005 ; 52.1 \pm 6.4$ to $10.1 \pm 2.7 \%$ at mid sites, $t$ test, $t_{7}=3.79, p<10^{-5} ; 55.7 \pm 6.7$ to $5.7 \pm 2.9 \%$ at far sites, $t$ test, $t_{9}=7.7, p<10^{-4}$; and $24.4 \pm 5.9 \%$ to $5.5 \pm$ $2.1 \%$ in control rats, $t$ test, $t_{12}=7.09, p<10^{-4}$; Fig. $4 A$ ). There were also no significant differences in modulation depth $\left(\mathrm{MD}_{\Delta}\right)$ with BMI learning $(102.5 \pm 22.5 \%, 111.8 \pm 18.5 \%, 130.2 \pm$ $19.3 \%$, and $120.3 \pm 18.2 \%$ change for $17,25,23$ units at near, mid, and far sites in stroke rats and 26 units in control rats, respectively, one-way ANOVA, $F_{(3,87)}=0.33, p=0.80$; Fig. $4 B$ ). Even when $\mathrm{MD}_{\Delta}$ was segregated for broad-width and narrowwidth units, there were no significant differences. Further, the 
A

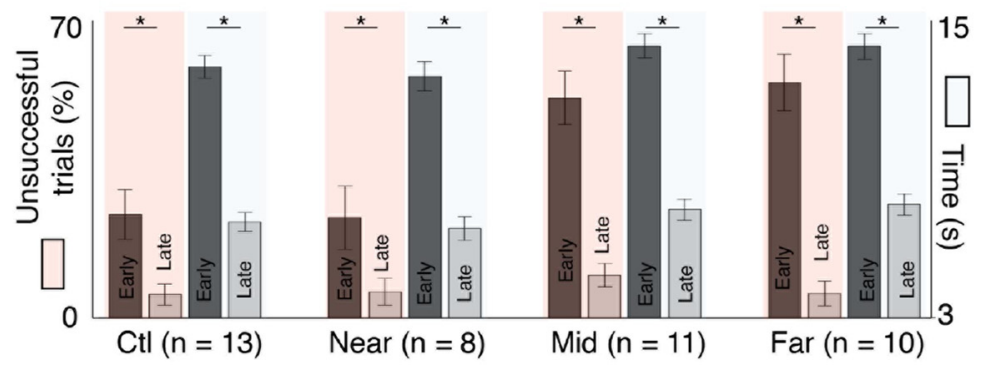

B

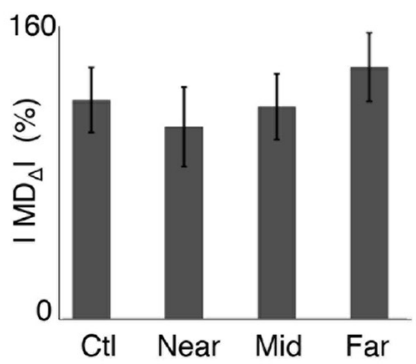

Figure 4. Comparison of control as a function of distance from the stroke. $A$, Comparison of the change in mean time to task completion for the three sites (highlighted in blue panels: early trials in left bar, late trials in right bar). Also shown is the change in unsuccessful trials with learning (highlighted in red panels: early trials in left bar, late trials in right bar). Error bars show $S E M .{ }^{*} p<0.01$. $\boldsymbol{B}$, Changes in $\mathrm{MD}_{\Delta}$ with learning.

slope of learning was also identical at near, mid, and far sites in stroke rats and in control rats. These sessions were conducted 1-4 weeks after stroke, when animals had a single-pellet reach accuracy of $13.9 \pm$ $1.8 \%$ (i.e., compared with the baseline period).

\section{Direct cortical control in the absence of motor recovery}

We next examined the relationship between upper-limb motor recovery and the ability to learn transforms using PLC neurons. The example in Figure $5 A$ illustrates that learning was possible even when rats were unable to attempt reaches. Across animals, we did not find a significant relationship between the ability to complete the physical reaching task (i.e., percentage relative to baseline accuracy rate) and either the reduction of unsuccessful trials $\left(R^{2}=2.5 \times 10^{-4}, p=0.93\right.$; Fig. $\left.5 B\right)$ or the time to trial completion during neuroprosthetic control $\left(R^{2}=0.021, p=\right.$ 0.45 ; Fig. $5 C$ ). This suggests a surprising dissociation between the capacity for volitional control of PLC spiking activity and the time course of motor recovery after stroke.

\section{Formation of cell assemblies}

We next investigated whether there was evidence for the formation of stable patterns of neural firing with direct neural control and learning (i.e., emergence of “cell assemblies"). Specifically, we used principal components analysis to identify significant "signal components" (see Materials and Methods). This method has been used to identify patterns of neural activity that emerge with learning (Peyrache et al., 2009; Lopes-dos-Santos et al., 2013; Gulati et al., 2014). It assesses for the emergence of stereotyped ensemble activity with practice and learning. For this analysis, we used both "direct" neural activity (i.e., neurons that were assigned to the transform) and "indirect" activity (i.e., neurons that are recorded but not causally linked to the transform; Ganguly et al., 2011; Koralek et al., 2012). Therefore, an increase in activation would indicate that there is greater coincident activation of both

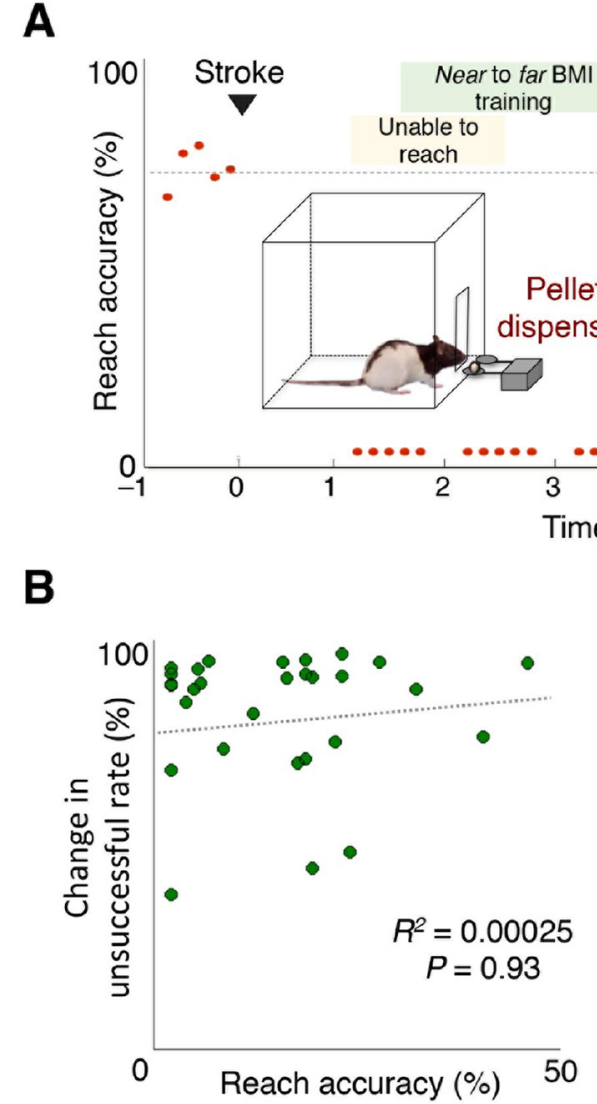

Figure 5. Relationship between upper-limb motor recovery and direct neural control. $\boldsymbol{A}$, Change in reach performance with recovery. "Unable to reach" indicates an inability to even attempt a reach. Subsequently, this animal remained unable to grasp pellets until after week 4. $\boldsymbol{B}$, Relationship between relative reach accuracy and the reduction in the number of unsuccessful trials during $B M I$ sessions in stroke rats. Values $\left(R^{2}\right.$ and $P$ ) represent the respective fit of a line using linear regression. Each dot represents one session. $C$, Relationship between relative reach accuracy and the percentage improvement in time to task completion.

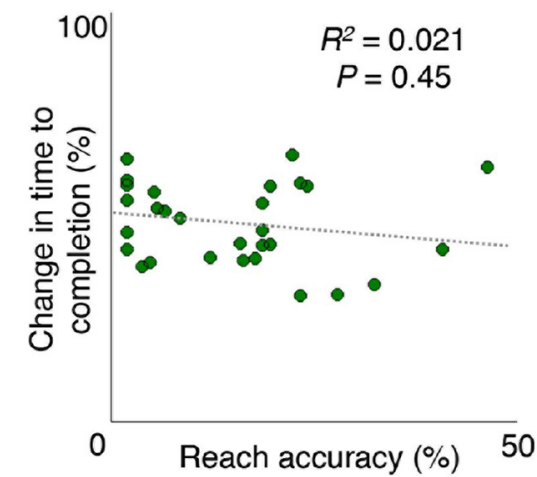

task-related direct and indirect neural activity and the formation of cell assemblies (Fig. 6A,B). Figure $6 A$ shows that the average activation strength increased from early to late trials. Figure $6 B$ shows that as the task performance improved in a session, the extent of stereotyped "cell assembly" activation became stronger. We found consistent evidence for cell assembly formation with practice (stroke BMI 29 sessions: early activation strength of $0.41 \pm 0.07$ and late activation strength: $0.83 \pm 0.15, t$ test, $\mathrm{t}_{28}=$ $-4.89, p<10^{-4}$; control BMI 13 sessions: $0.51 \pm 0.11$ to $1.11 \pm$ $0.22, t$ test, $\mathrm{t}_{12}=-2.36, p<0.05$; Fig. $6 C$ ). When we evaluated prinicipal component scores for broad-width and narrow-width cells involved in stroke BMI, we did not find any difference, in- 
A

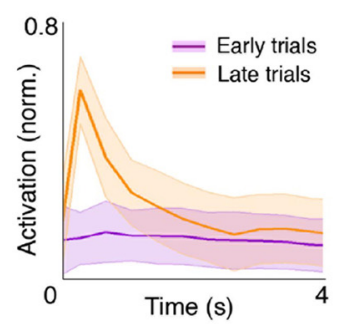

B

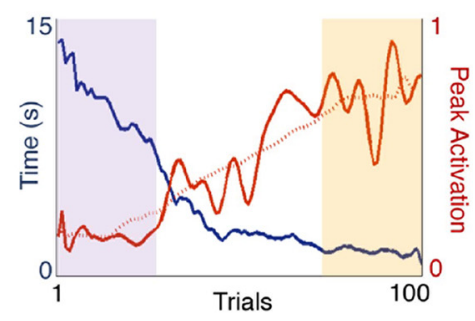

C

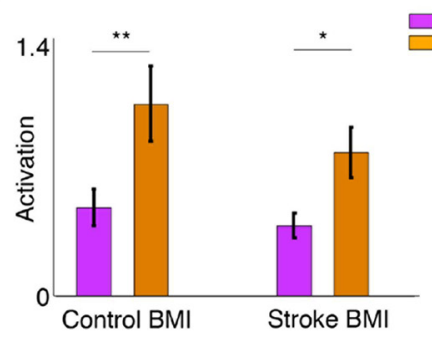

Figure 6. Emergence of functional cell assemblies in the PLC. $\boldsymbol{A}$, Shown are the mean activation profiles for early versus late trials from a representative session. Shaded region is the SEM. $\boldsymbol{B}$, Solid dark blue line is the moving average mean using 20 trials of the time to task completion for the session used in $A$. The solid red line is a continuous trial-by-trial measure of the activation strength. The dotted line in dark red is the moving average mean of the activation strength using 20 trials. Early and late portions of the trials are highlighted in same colors as $\boldsymbol{A}$. C, Comparison of the respective changes in activation for intact animals BMI sessions and BMI sessions in stroke animals. Error bars indicate SEM. ${ }^{*} p<0.01 ;{ }^{* *} p<10^{-4}$.

A

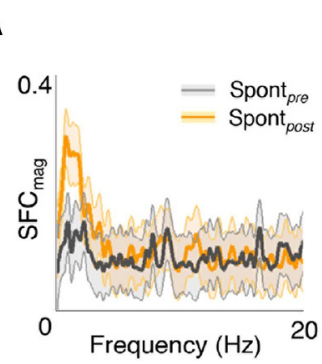

B

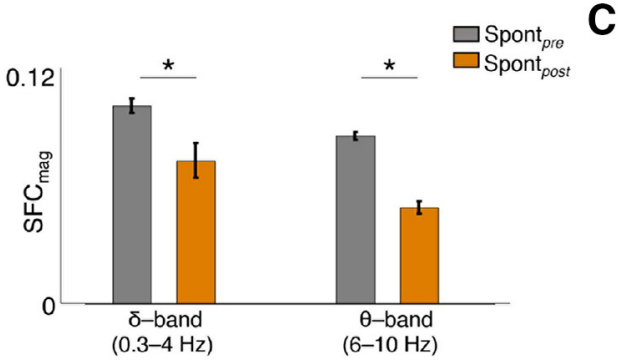

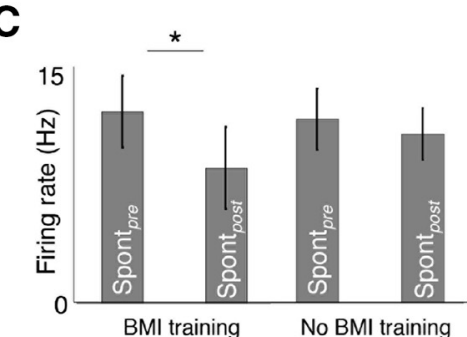

Figure 7. Persistent change in cortical state after direct neural control. $A$, Example of a persistent reduction of $\mathrm{SF}_{\mathrm{mag}}$ for a direct unit after a learning session. $B$, Averaged $\mathrm{SFC}_{\mathrm{mag}}$ for direct units before and after first training (i.e., in the $\delta$ - and $\theta$-frequency bands). C, Averaged firing rate for direct units before and after direct neural control in stroke animal with BMI training and no BMI training. ${ }^{*} p<0.05$.

dicating that both cell types participated in a similar way in assembly formation (PC scores for narrow-width cells: $-0.021 \pm$ $0.019 \%$, broad-width cells: $0.016 \pm 0.029 \%$; $t$ test, $\mathrm{t}_{63}=0.75, p=$ $0.46)$. Therefore, cortical networks in the PLC appear to be capable of forming and stabilizing new large-scale functional associations among emergent ensembles.

\section{Persistent changes in spike-field coupling}

We next evaluated whether prolonged direct neural control persistently modified the spike-field relationship in the PLC. Interestingly, we found that, during spontaneously recorded activity after the first successful training session, the $\mathrm{SFC}_{\text {mag }}$ for direct neurons that underwent direct neural control reduced significantly ( $p<0.05, n=10$ for $\delta$ and $\theta$ frequency range; Fig. $7 A, B)$. Furthermore, we found that the spontaneous firing rates of direct units reduced significantly $(p<0.05$; Fig. $7 C)$. When we checked for firing rates in three additional rats that underwent stroke but no BMI training, the firing rates did not change $(n=72, p>0.05$; Fig. $7 C$ ). The firing rates were equalized before $\mathrm{SFC}_{\text {mag }}$ calculation (see Materials and Methods). In addition, the power in these frequency bands appeared to reduce slightly, but this was not statistically significant. Therefore, the spike-field relationship for neurons that underwent direct neural control was persistently modified after the training period.

\section{Discussion}

Our results indicate that spiking activity from neurons in the PLC can be used to achieve neuroprosthetic control. There was no difference relative to distance from the stroke site or compared with intact animals. Interestingly, the observed abnormal slowing of the LFP and its associated modulation of neural firing did not appear to impede the network-level physiological plasticity necessary to achieve neuroprosthetic control. This further indicates that the microstructural and physiological reorganization after stroke is sufficient to permit direct cortical control and the formation of functional cell assemblies. Moreover, we also found a surprising dissociation between the capacity for BMI control from the PLC and the process of motor recovery.

Our findings have direct implications for the development of intracortical BMIs compatible with cortical injury. In our experiments, rodents were required to modulate PLC neural activity volitionally to control an artificial actuator; volitional modulation of neural activity is at the core of neuroprosthetic control (Fetz, 1969; Ganguly and Carmena, 2009; Ganguly et al., 2011). We also found that the injury triggered slow oscillations (i.e., in the $\delta$ and $\theta$ frequency range; Van Huffelen et al., 1984; Laaksonen et al., 2013) did not necessarily preclude learning neuroprosthetic control. Moreover, the elevated firing rates of the putative pyramidal cells (i.e., broader action potential widths) also did not appear to impede learning. Although a general hyperexcitability poststroke has been observed using multiunit recordings (Schiene et al., 1996; Hagemann et al., 1998; Carmichael and Chesselet, 2002), we specifically found that such hyperexcitability may be significantly more pronounced for regular-spiking pyramidal cells. It is possible that the altered local and long-range connectivity (Dancause, 2006), the changes in receptor profiles (Schiene et al., 1996), and/or the changes in extracellular neurotransmitter content (Clarkson et al., 2010) affects the two classes of neurons differentially. Remarkably, despite the abnormal oscillations and the elevated baseline firing rates, we found clear evidence for robust volitional control of the perilesional neural activity. Moreover, such control was also possible even when physical upper limb movements were severely impaired. This suggests that the PLC in subjects with permanent deficits may be capable of supporting neuroprosthetic 
control. Together, our results indicate that, despite the disrupted connectivity after stroke, the PLC may serve as an effective target for intracortical neural interfaces specifically designed for stroke patients.

We also found that direct neural control modified neural activity patterns outside of the training period (i.e., changes in spontaneous activity after training compared with that before training). Specifically, we found that the firing rates of the conditioned direct neurons became significantly reduced and approached that of normal animals. Moreover, these neurons were significantly less likely to be modulated by the abnormal lowfrequency oscillations evident in the PLC. These findings suggest that direct neural control can trigger longer-lasting plasticity through modulation of the functional connectivity. It may be consistent with our recent finding of "offline" processing during slow-wave sleep after neuroprosthetic learning (Gulati et al., 2014). The observed persistent changes in neural firing may also be closely related to the growing body of work suggesting that "neurofeedback" can be used to treat a range of neurological and psychiatric disorders (Strehl et al., 2006; Birbaumer et al., 2009; Ramos-Murguialday et al., 2013). During neurofeedback, noninvasive scalp EEG recordings are used to assess brain states and to provide feedback. Interestingly, a recent study found that volitional modulation of the $\mu$-rhythm using neurofeedback could promote recovery after stroke (Birbaumer and Cohen, 2007; Ramos-Murguialday et al., 2013). It is difficult to compare our invasive recordings from a single cortical area with scalp EEG recordings directly; moreover, the exact cortical and subcortical generators of the $\mu$-rhythm remain unclear. However, it suggests the possibility that feedback-dependent $\mu$-rhythm modulation may exert its effects, at least in part, by modifying the activity of the PLC.

Interestingly, the notable dissociation between the temporal course and the extent of recovery and the ability for direct neural control suggests that the functional state and the potential for plasticity of the PLC may not be sufficient to support motor recovery. There is increasing evidence that volitional modulation of neural activity requires both top-down and local processes (Fetz, 2007; Halder et al., 2011). Moreover, it requires the recruitment of NMDA-R-dependent plasticity (Koralek et al., 2012). Together, the evidence suggests that existing cortical and subcortical mechanisms of plasticity are recruited during the process of learning direct neural control. In this context, the ability to achieve successfully direct neural control of the PLC suggests that mechanisms of plasticity are present and capable of being recruited. It further suggests that such mechanisms are not necessarily sufficient to promote motor recovery. This may be consistent with the finding in clinical stroke studies that corticospinal projection integrity is essential for recovery of motor function (Stinear et al., 2012; Ganguly et al., 2013). In other words, whereas the PLC is capable of expressing plasticity, the lack of a substrate to transmit the information ultimately prevents motor recovery. Moreover, our finding of robust direct neural control of the PLC may have implications for emerging therapeutics; for example, cell-based therapies aim to augment the plasticity and the recovery potential of cortical areas after stroke (Bliss et al., 2007).

In summary, our results indicate that direct neural control and learning was possible from the immediate PLC. There was surprisingly no difference relative to distance from the stroke site or compared with intact animals. More broadly, our results suggest that PLC may be a viable substrate for intracortical neural interfaces in patients with severe disability after stroke.

\section{References}

Arduin PJ, Frégnac Y, Shulz DE, Ego-Stengel V (2013) “Master" neurons induced by operant conditioning in rat motor cortex during a brainmachine interface task. J Neurosci 33:8308-8320. CrossRef Medline

Biernaskie J, Corbett D (2001) Enriched rehabilitative training promotes improved forelimb motor function and enhanced dendritic growth after focal ischemic injury. J Neurosci 21:5272-5280. Medline

Birbaumer N, Cohen LG (2007) Brain-computer interfaces: communication and restoration of movement in paralysis. J Physiol 579:621-636. CrossRef Medline

Birbaumer N, Ramos Murguialday A, Weber C, Montoya P (2009) Neurofeedback and brain-computer interface clinical applications. Int Rev Neurobiol 86:107-117. CrossRef Medline

Bliss T, Guzman R, Daadi M, Steinberg GK (2007) Cell transplantation therapy for stroke. Stroke 38:817-826. CrossRef Medline

Brinkman J, Kuypers HG (1973) Cerebral control of contralateral and ipsilateral arm, hand and finger movements in the split-brain rhesus monkey. Brain 96:653-674. CrossRef Medline

Brown CE, Boyd JD, Murphy TH (2010) Longitudinal in vivo imaging reveals balanced and branch-specific remodeling of mature cortical pyramidal dendritic arbors after stroke. J Cereb Blood Flow Metab 30:783791. CrossRef Medline

Bundy DT, Wronkiewicz M, Sharma M, Moran DW, Corbetta M, Leuthardt EC (2012) Using ipsilateral motor signals in the unaffected cerebral hemisphere as a signal platform for brain-computer interfaces in hemiplegic stroke survivors. J Neural Eng 9:036011. CrossRef Medline

Carmena JM, Lebedev MA, Crist RE, O’Doherty JE, Santucci DM, Dimitrov DF, Patil PG, Henriquez CS, Nicolelis MA (2003) Learning to control a brain-machine interface for reaching and grasping by primates. PLoS Biol 1:E42. Medline

Carmichael ST, Chesselet MF (2002) Synchronous neuronal activity is a signal for axonal sprouting after cortical lesions in the adult. J Neurosci 22:6062-6070. Medline

Chapin JK, Moxon KA, Markowitz RS, Nicolelis MA (1999) Real-time control of a robot arm using simultaneously recorded neurons in the motor cortex. Nat Neurosci 2:664-670. CrossRef Medline

Clarkson AN, Huang BS, Macisaac SE, Mody I, Carmichael ST (2010) Reducing excessive GABA-mediated tonic inhibition promotes functional recovery after stroke. Nature 468:305-309. CrossRef Medline

Collinger JL, Wodlinger B, Downey JE, Wang W, Tyler-Kabara EC, Weber DJ, McMorland AJ, Velliste M, Boninger ML, Schwartz AB (2013) Highperformance neuroprosthetic control by an individual with tetraplegia. Lancet 381:557-564. CrossRef Medline

Courtin J, Chaudun F, Rozeske RR, Karalis N, Gonzalez-Campo C, Wurtz H, Abdi A, Baufreton J, Bienvenu TC, Herry C (2014) Prefrontal parvalbumin interneurons shape neuronal activity to drive fear expression. Nature 505:92-96. Medline

Cramer SC (2008) Repairing the human brain after stroke: I. Mechanisms of spontaneous recovery. Ann Neurol 63:272-287. CrossRef Medline

Daly JJ, Wolpaw JR (2008) Brain-computer interfaces in neurological rehabilitation. Lancet Neurol 7:1032-1043. CrossRef Medline

Dancause N (2006) Vicarious function of remote cortex following stroke: recent evidence from human and animal studies. Neuroscientist 12:489499. CrossRef Medline

Fetz EE (1969) Operant conditioning of cortical unit activity. Science 163: 955-958. CrossRef Medline

Fetz EE (2007) Volitional control of neural activity: implications for braincomputer interfaces. J Physiol 579:571-579. CrossRef Medline

Foroud A, Whishaw IQ (2006) Changes in the kinematic structure and nonkinematic features of movements during skilled reaching after stroke: a Laban Movement Analysis in two case studies. J Neurosci Methods 158: 137-149. CrossRef Medline

Ganguly K, Carmena JM (2009) Emergence of a stable cortical map for neuroprosthetic control. Plos Biol 7:e1000153. CrossRef Medline

Ganguly K, Secundo L, Ranade G, Orsborn A, Chang EF, Dimitrov DF, Wallis JD, Barbaro NM, Knight RT, Carmena JM (2009) Cortical representation of ipsilateral arm movements in monkey and man. J Neurosci 29: 12948-12956. CrossRef Medline

Ganguly K, Dimitrov DF, Wallis JD, Carmena JM (2011) Reversible largescale modification of cortical networks during neuroprosthetic control. Nat Neurosci 14:662-667. CrossRef Medline 
Ganguly K, Byl NN, Abrams GM (2013) Neurorehabilitation: Motor recovery after stroke as an example. Ann Neurol 74:373-381. CrossRef Medline

Guggenmos DJ, Azin M, Barbay S, Mahnken JD, Dunham C, Mohseni P, Nudo RJ (2013) Restoration of function after brain damage using a neural prosthesis. Proc Natl Acad Sci U S A 110:21177-21182. CrossRef Medline

Gulati T, Ramanathan DS, Wong CC, Ganguly K (2014) Reactivation of emergent task-related ensembles during slow-wave sleep after neuroprosthetic learning. Nat Neurosci 17:1107-1113. CrossRef Medline

Hagemann G, Redecker C, Neumann-Haefelin T, Freund HJ, Witte OW (1998) Increased long-term potentiation in the surround of experimentally induced focal cortical infarction. Ann Neurol 44:255-258. CrossRef Medline

Halder S, Agorastos D, Veit R, Hammer EM, Lee S, Varkuti B, Bogdan M, Rosenstiel W, Birbaumer N, Kübler A (2011) Neural mechanisms of brain-computer interface control. Neuroimage 55:1779-1790. CrossRef Medline

Hochberg LR, Serruya MD, Friehs GM, Mukand JA, Saleh M, Caplan AH, Branner A, Chen D, Penn RD, Donoghue JP (2006) Neuronal ensemble control of prosthetic devices by a human with tetraplegia. Nature 442: 164-171. CrossRef Medline

Hochberg LR, Bacher D, Jarosiewicz B, Masse NY, Simeral JD, Vogel J, Haddadin S, Liu J, Cash SS, van der Smagt P, Donoghue JP (2012) Reach and grasp by people with tetraplegia using a neurally controlled robotic arm. Nature 485:372-375. CrossRef Medline

Hummel FC, Cohen LG (2006) Non-invasive brain stimulation: a new strategy to improve neurorehabilitation after stroke? Lancet Neurol 5:708-712. CrossRef Medline

Isomura Y, Harukuni R, Takekawa T, Aizawa H, Fukai T (2009) Microcircuitry coordination of cortical motor information in self-initiation of voluntary movements. Nat Neurosci 12:1586-1593. CrossRef Medline

Jarosiewicz B, Chase SM, Fraser GW, Velliste M, Kass RE, Schwartz AB (2008) Functional network reorganization during learning in a braincomputer interface paradigm. Proc Natl Acad Sci U S A 105:1948619491. CrossRef Medline

Koralek AC, Long JD, Costa RM, Carmena JM (2010) Corticostriatal dynamics during learning and performance of a neuroprosthetic task. Conf Proc IEEE Eng Med Biol Soc 2010:2682-2685. Medline

Koralek AC, Jin X, Long JD 2nd, Costa RM, Carmena JM (2012) Corticostriatal plasticity is necessary for learning intentional neuroprosthetic skills. Nature 483:331-335. CrossRef Medline

Laaksonen K, Helle L, Parkkonen L, Kirveskari E, Mäkelä JP, Mustanoja S, Tatlisumak T, Kaste M, Forss N (2013) Alterations in spontaneous brain oscillations during stroke recovery. PLoS One 8:e61146. CrossRef Medline

Langhorne P, Bernhardt J, Kwakkel G (2011) Stroke rehabilitation. Lancet 377:1693-1702. CrossRef Medline

Lopes-dos-Santos V, Ribeiro S, Tort AB (2013) Detecting cell assemblies in large neuronal populations. J Neurosci Methods 220:149-166. CrossRef Medline

Mitchell JF, Sundberg KA, Reynolds JH (2009) Spatial attention decorrelates intrinsic activity fluctuations in macaque area V4. Neuron 63:879888. CrossRef Medline

Mitra P, Bokil H (2008) Observed brain dynamics. New York: OUP.

Moritz CT, Perlmutter SI, Fetz EE (2008) Direct control of paralysed muscles by cortical neurons. Nature 456:639-642. CrossRef Medline

Murphy TH, Corbett D (2009) Plasticity during stroke recovery: from synapse to behaviour. Nat Rev Neurosci 10:861-872. CrossRef Medline

Musallam S, Corneil BD, Greger B, Scherberger H, Andersen RA (2004) Cognitive control signals for neural prosthetics. Science 305:258-262. CrossRef Medline
Norrving B, Kissela B (2013) The global burden of stroke and need for a continuum of care. Neurology 80:S5-12. CrossRef Medline

Nudo RJ, Milliken GW (1996) Reorganization of movement representations in primary motor cortex following focal ischemic infarcts in adult squirrel monkeys. J Neurophysiol 75:2144-2149. Medline

Nudo RJ, Wise BM, SiFuentes F, Milliken GW (1996) Neural substrates for the effects of rehabilitative training on motor recovery after ischemic infarct. Science 272:1791-1794. CrossRef Medline

Peyrache A, Khamassi M, Benchenane K, Wiener SI, Battaglia FP (2009) Replay of rule-learning related neural patterns in the prefrontal cortex during sleep. Nat Neurosci 12:919-926. CrossRef Medline

Ramanathan D, Conner JM, Tuszynski MH (2006) A form of motor cortical plasticity that correlates with recovery of function after brain injury. Proc Natl Acad Sci U S A 103:11370-11375. CrossRef Medline

Ramos-Murguialday A, Broetz D, Rea M, Läer L, Yilmaz O, Brasil FL, Liberati G, Curado MR, Garcia-Cossio E, Vyziotis A, Cho W, Agostini M, Soares E, Soekadar S, Caria A, Cohen LG, Birbaumer N (2013) Brain-machine interface in chronic stroke rehabilitation: a controlled study. Ann Neurol 74:100-108. CrossRef Medline

Rutishauser U, Ross IB, Mamelak AN, Schuman EM (2010) Human memory strength is predicted by theta-frequency phase-locking of single neurons. Nature 464:903-907. CrossRef Medline

Santhanam G, Ryu SI, Yu BM, Afshar A, Shenoy KV (2006) A highperformance brain-computer interface. Nature 442:195-198. CrossRef Medline

Schiene K, Bruehl C, Zilles K, Qü M, Hagemann G, Kraemer M, Witte OW (1996) Neuronal hyperexcitability and reduction of GABAA-receptor expression in the surround of cerebral photothrombosis. J Cereb Blood Flow Metab 16:906-914. Medline

Serruya MD, Hatsopoulos NG, Paninski L, Fellows MR, Donoghue JP (2002) Instant neural control of a movement signal. Nature 416:141-142. CrossRef Medline

Stinear CM, Barber PA, Petoe M, Anwar S, Byblow WD (2012) The PREP algorithm predicts potential for upper limb recovery after stroke. Brain 135:2527-2535. CrossRef Medline

Strehl U, Leins U, Goth G, Klinger C, Hinterberger T, Birbaumer N (2006) Self-regulation of slow cortical potentials: a new treatment for children with attention-deficit/hyperactivity disorder. Pediatrics 118:e1530-1540. CrossRef Medline

Suner S, Fellows MR, Vargas-Irwin C, Nakata GK, Donoghue JP (2005) Reliability of signals from a chronically implanted, silicon-based electrode array in non-human primate primary motor cortex. IEEE Trans Neural Syst Rehabil Eng 13:524-541. CrossRef Medline

Taylor DM, Tillery SI, Schwartz AB (2002) Direct cortical control of 3D neuroprosthetic devices. Science 296:1829-1832. CrossRef Medline

Van Huffelen AC, Poortvliet DC, Van der Wulp CJ (1984) Quantitative electroencephalography in cerebral ischemia: detection of abnormalities in "normal” EEGs. Prog Brain Res 62:3-28. CrossRef Medline

Velliste M, Perel S, Spalding MC, Whitford AS, Schwartz AB (2008) Cortical control of a prosthetic arm for self-feeding. Nature 453:1098-1101. CrossRef Medline

Vinck M, Womelsdorf T, Buffalo EA, Desimone R, Fries P (2013) Attentional modulation of cell-class-specific gamma-band synchronization in awake monkey area v4. Neuron 80:1077-1089. CrossRef Medline

Ward NS (2004) Functional reorganization of the cerebral motor system after stroke. Curr Opin Neurol 17:725-730. CrossRef Medline

Wong CC, Ramanathan DS, Gulati T, Won SJ, Ganguly K (2015) An automated behavioral box to assess forelimb function in rats. J Neurosci Methods 246:30-37. CrossRef Medline

Zeitler M, Fries P, Gielen S (2006) Assessing neuronal coherence with single-unit, multi-unit, and local field potentials. Neural Comput 18: 2256-2281. CrossRef Medline 